\title{
Bare NPs: Kind-referring, Indefinites, Both, or Neither?
}

\author{
Manfred Krifka \\ Humboldt-Universität zu Berlin \\ and Zentrum für Allgemeine Sprachwissenschaft (ZAS), Berlin
}

\section{Generally shared assumption about Genericity}

It is generally assumed that there are two types of genericity, called characterizing statements and kind reference in Krifka et al. (1995). Characterizing statements express generalizations about sets of entities or situations, cf. (1); kind reference involves reference to an entity that is related to specimens, cf. (2).
a. A potato contains vitamin $\mathrm{C}$.
'For all/typical $\mathrm{x}$ : if $\mathrm{x}$ is a potato, $\mathrm{x}$ contains vitamin $\mathrm{C}$.'
b. A gentleman opens doors for ladies.
'For all/typical $\mathrm{x}$ : If $\mathrm{x}$ is a gentleman, he opens doors for ladies.'
a. The potato was first cultivated in South America.
'The kind tuber tuberosum was first cultivated in South America.'
b. Shockley invented the transistor.
'Shockley conceived of, and realized, the kind of the transistor.'

There are mixed cases, characterizing statements about the specimens of kinds:

(3) The potato contains vitamin C.

'For all/typical specimens of Tuber tuberosum $\mathrm{x}, \mathrm{x}$ contains vitamin C.

We distinguish these types because indefinite NPs in characterizing statements cannot in general be replaced by definite NPs, and def inite kind-referring NPs cannot in general be replaced by indefinite NPs, cf. (4). Sentence (4.b) is possible on the taxonomic interpretation, referring to a subspecies of tuber tuberosum.
a. *The gentleman opens doors for ladies.
b. *A potato was first cultivated in South America.

Of course, definite and indefinite singular NPs do not only occur in generic expressions. Definite singular NPs can also refer to some salient or unique object, cf. (5.a), and indefinite NPs can also introduce a new entity, cf. (5.b).
a. The potato rolled out of the bag.
b. A potato rolled out of the bag.

Definite singular NPs are assumed to be systematically ambiguous, that is, polysemous: They can either refer to the kind, or to some unique or salient specimen belonging to the kind. A predicate like is extinct, or was cultivated in the South America, selects for the kind reading; a predicate like rolled out of the bag selects for the object reading. We can represent these two readings as in (6), where $t$ is an operator that maps a predicate to the unique or most salient entity it applies to.

$$
\begin{aligned}
& \text { a. ROLLED_OUT_OF_THE_BAG(IPOTATO) } \\
& \text { b. FIRST_CULTIVATED_IN_SOUTH_AMERICA(TUBER_TUBEROSUM) }
\end{aligned}
$$

Indefinite singular NPs are generally assumed to be not ambiguous. Their apparently different interpretation in sentences like (1.a) and (5.b) is a result of the pres- 
ence of a quantificational operator in characterizing statements, quite similar as in sentences with overt adverbial quantifiers, as in A potato always contains vitamin $C$ (cf. Heim (1982)). What is common to all indefinite NPs is that they introduce a variable that is constrained by the predicate expressed by the indefinite. If the NP is interpreted in the restrictor of a quantificational operator (like always, or the generic operator in characterizing sentences called GEN), the variable is associated with this operator, cf. (7.a). If there is no quantificational operator around, the variable is associated by existential closure, here indicated by $\exists$ (cf. (7.b)).

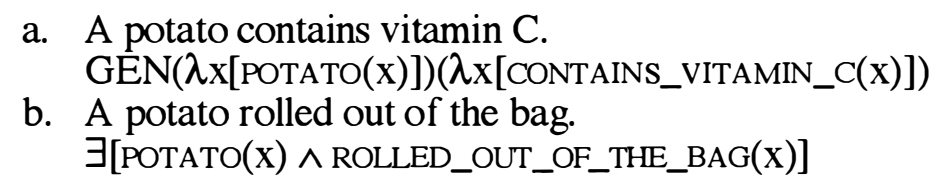

It is also possible to give a more ordinary semantics to indefinites where they are always associated with an existential quantifier. This quantifier then has to be treated as dynamic, which will result in the same semantic interpretation (cf. Rooth (1987)).

\section{Different opinions about Bare NPs}

The interpretation of bare NPs - that is, NPs without articles, mass nouns like bronze and plurals like potatoes - is controversial. They appear in contexts that select for kind reference, cf. (8.a), and in characterizing statements, cf. (8.b). And they have non-generic uses, as in (8.c).
a. Potatoes were first cultivated in South America.
Bronze was invented around $3000 \mathrm{BC}$
b Potatoes contain vitamin C. / Gentlemen open doors for ladies.
Bronze was used for jewelry and weaponry.
c. Potatoes rolled out of the bag.
Bronze was detected in the remnants of the furnace.

There are essentially two types of theories for bare NPs: The kind-reference analysis of Carlson (1977) holds that they uniformly refer to kinds. The apparent object-related use as in (8.c) is explained by a general property of episodic predicates: If applied to a kind, they introduce, by existential quantification, a specimen of that kind. Writing $R(y, x)$ to indicate that $y$ is a specimen, or realization, of the kind $x$, we can give the following analyses:
a. Potatoes were first cultivated in South America.
FIRST_CULTIVATED_IN_SOUTH_AMERICA(TUBER_TUBEROSUM)
b. Potatoes contain vitamin $\mathrm{C}$.
CONTAIN_VITAMIN_C(TUBER_TUBEROSUM)
c. Potatoes rolled out of the bag.
$\lambda x \exists y[R(y, x) \wedge$ ROLLED_OUT_OF_THE_BAG(y)](TUBER_TUBEROSUM)
$=\exists y\left[R\left(y, T U B E R \_T U B E R O S U M\right) \wedge\right.$ ROLLED_OUT_OF_THE_BAG(y)]

The ambiguity analysis, as proposed by Wilkinson (1991) and Gerstner-Link \& Krifka (1993), holds that bare NPs are systematically ambiguous (i.e., polysemous). They either refer to a kind, like definite singular NPs, or are the plural counterpart of indef inite singular NPs. (8.a) is interpreted just as in the kind-reference analysis, but $(8 . b, c)$ get the interpretation of their singular counterparts, $(7 . a, b)$ : 
a. Potatoes contain vitamin $\mathrm{C}$.

GEN(ヨx[POTATOEs(x)])(CONTAINS_VITAMIN_C(x))

b. Potatoes rolled out of the bag.

$\exists x[$ POTATOES$(\mathrm{x})] \wedge$ ROLLED_OUT_OF_THE_BAG(x)

There are a number of arguments for the kind-reference analysis of bare NPs, and some against it that argue for the ambiguity hypothesis, which I will review here.

\subsection{Arguments for the kind-referring analysis.}

First, Carlson (1977) observed that the readings of sentences are determined by their predicate. The sentence Potatoes are rolling out of the bag only has a non-generic interpretation, and Potatoes contain vitamin $C$ only a generic one. His theory accounts for this fact. However, we find a similar lack of ambiguity with singular indefinites, as in A potato was rolling out of the bag and A potato contains vitamin $C$. Carlson's theory does not generalize to these cases, as singular indefinites certainly do not denote kinds.

Second, it was shown by Carlson (1977) that anaphoric bindings are possible across kind-referring and apparently object-referring uses, as in (11).

(11) a. John bought potatoes because they contain vitamin C.

b. Watermelons contain iron, so John of ten buys them / one.

Assumes that all of these NPs are kind-referring explains these cases: Definite pronouns like they also refer to the kind, and indefinite pronouns like one pick up a kind and introduce a specimen of it. But again, singular indef inites behave similar:

a. John bought a potato / some potatoes because they contain vitamin C.

b. A watermelon contains vitamin $\mathrm{C}$, so John of ten buys them / one.

A third argument was put forward by Schubert and Pelletier (1987), who argue that predicates of different types can be conjoined:

${ }^{(? ?)}$ Frogs are reptiles and are croaking right now in front of my window. $\lambda \mathrm{x}\left[\operatorname{REPTILES}(\mathrm{x}) \wedge \lambda \mathrm{x} \exists \mathrm{y}\left[\mathrm{R}(\mathrm{y}, \mathrm{x}) \wedge \mathrm{BE} \_\mathrm{CROAKING}(\mathrm{y})\right]\right](\mathrm{RANO})$

The kind-reference analysis explains such cases easily. But informants judge such examples as problematic, essentially not better than parallel sentences with singular indefinite NPs, as in ${ }^{? ?} A$ frog is a reptile and is croaking right now in front of my window. However, cases like (14), which make a similar point, are fine.

(14) Frogs, which are reptiles, are croaking right now in front of my window.

Of Carlson's original arguments for the kind-referring analysis of bare NPs, the most convincing ones are those that relate to their scopal behavior. Bare NPs have a clear pref erence for narrow scope, whereas singular indef inite NPs may have narrow or wide scope, with respect to other operators such as negation, quantifiers, or attitude verbs. For example, (15.a) has a non-contradictory reading because a dog can have wide scope with respect to negation, which is lacking for (15.b). This is predicted if the existential quantifier is introduced by the lexical predicate.

a. A dog is here, and a dog is not here.

i. $\exists x[\operatorname{DOG}(\mathrm{x}) \wedge \operatorname{HERE}(\mathrm{x})] \wedge \exists \mathrm{x}[\operatorname{DOG}(\mathrm{x}) \wedge \neg \operatorname{HERE}(\mathrm{x})]$

ii. $\exists x[\operatorname{DOG}(x) \wedge \operatorname{HERE}(x)] \wedge \neg \exists x[\operatorname{DOG}(x) \wedge \operatorname{HERE}(x)]$ (contradict.) 
b. Dogs are here, and dogs are not here. $\lambda \mathrm{x} \exists \mathrm{y}[\mathrm{R}(\mathrm{y}, \mathrm{x}) \wedge \operatorname{HERE}(\mathrm{y})](\mathrm{CANIS}) \wedge \neg[\lambda \mathrm{x} \exists \mathrm{x}[\mathrm{R}(\mathrm{y}, \mathrm{x}) \wedge \mathrm{HERE}(\mathrm{y})](\mathrm{CANIS})]$ $\cdot=\exists \mathrm{y}[\mathrm{R}(\mathrm{y}, \mathrm{CANIS}) \wedge \operatorname{HERE}(\mathrm{y})] \wedge \neg \exists \mathrm{y}[\mathrm{R}(\mathrm{y}, \mathrm{CANIS}) \wedge \mathrm{HERE}(\mathrm{y})]($ contrad. $)$.

Similarly, while the singular indefinite NP in (16.a) has a narrow-scope and a widescope reading, the bare NP in (16.b) appears to have only a narrow-scope reading.
a. Minnie wants to talk to a psychiatrist
(non-specific or specific)
i. $\quad$ WANT(MINNIE, $\left.\lambda x\left[\lambda P \exists y[\operatorname{PSYCHIATRIST}(y) \wedge \mathrm{P}(\mathrm{y})]\left(\lambda y\left[\operatorname{TALK} \_T O(x, y)\right]\right)\right]\right)$

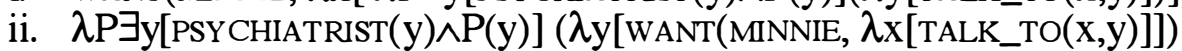
$\begin{array}{ll}\text { b. Minnie wants to talk to psychiatrists. } & \text { (non-specific only) } \\ \text { WANT(MINNIE, } \lambda x[\lambda y \exists z[R(z, y) \wedge \text { TALK_TO(x,z)](PSYCHIATRIST) }] \text { ) }\end{array}$

A variant of the anaphora argument was put forward by Rooth (1985). Consider (17.a), as a report about a peace meeting after an interplanetary war. Anaphoric binding is possible, even though Martians appears to refer to some Martians, and themselves to the kind. Such bindings are not possible for non-bare indefinites, as in (17.b.c). This is as predicted by the kind-referring analysis, for which Martians refers to a kind (cf. the analysis given for (17.a). A similar argument involves the binding of the subject position of indefinites, PRO, cf. (18).

a. At the meeting, Martians presented themselves as almost extinct. $\exists x\left[R\left(x, H O M O \_M A R T I E N S I S\right) \wedge\right.$ PRESENTED_AS_EXTINCT(x, HOMO_MART.)]

b. *At the meeting, a Martian presented themselves/itself as almost extinct.

c. *At the meeting, some Martians presented themselves as almost extinct.

a. At the meeting, Martians claimed [PRO to be almost extinct].

b. At the meeting, some Martians claimed [PRO to be almost extinct].

Another argument for a the kind-referring analysis was brought forward in Dayal (2002). In languages that allow for bare singular count noun NPs like Hindi and Russian, bare singulars and bare plurals behave differently with respect to scope effects. Take the following Russian examples:

$$
\begin{aligned}
& \text { a. \#Sobaka byla vesde. } \\
& \text { dog.sG was.sG everywhere } \\
& \text { 'A dog was everywhere.' }
\end{aligned}
$$
b. Sobaki byli vesde. dog.PL was.PL everywhere 'Dogs were everywhere.'

(19.a) is strange because it suggests that one and the same dog was everywhere. Dayal argues that this difference can be captured if we assume that bare singulars refer to kinds that allow only for single instantiations in a particular situation, which according to her is similar to definite-generic NPs like the dog. But a variant of the ambiguity theory could deal with this phenomenon equally well. We would have to assume that bare singular NPs introduce new discourse referents under the presupposition that they are unique in the situation talked about.

\subsection{Arguments for the ambiguity analysis}

There are some observations that pose problems for the kind-reference analysis and argue for the possibility that bare NPs can be interpreted like indefinites.

The kind-reference analysis is problematic because it stipulates that bare NPs, like potato, and singular definite generic NPs, like the potato, both refer to kinds. But they behave differently in episodic sentences; (20.a) cannot be used when some potatoes rolled out of the bag, in contrast to (20.b). 
b. Potatoes rolled out of the bag.

To be sure, there are theories that assume that the kinds bare NPs refer to and the kinds definite NPs refer to are different; for example, Chierchia (1998) and Dayal (2002) hold that the latter have unique representations. But even then (20.a) should be interpretable, saying that the potatoes of the situation talked about rolled out of the bag.

Another problem was discovered by Carlson (1989), who observes that his original theory cannot be right in the face of examples like (21).

Hurricanes arise in this part of the Pacific.

i. 'For hurricanes in general it holds: They arise in this part of the Pacific.'

ii. 'For this part of the P. it holds: There are hurricanes that arise there.'

The kind-referring analysis gives us only reading (21.i). Reading (ii) can be explained if hurricanes is an indefinite NP. Notice that singular indefinite NP behave in the same way; for example, (22.a) and (b) have similar interpretations (i), (ii).
a. Frenchmen wear berets.
b. A Frenchmen wears a beret.
i. For Frenchmen in general it holds: They were berets.
ii. For berets in general holds: They are worn by Frenchmen.

Prosody can distinguish between these readings: Accent on the object will result in reading (i), accent on the subject in reading (ii). This can be captured in different ways - by assuming that adverbial quantification is sensitive to focus, cf. Rooth (1985, 1995), or to givenness presuppositions expressed by deaccenting, cf. Krifka (2001). The accentual differences are reflected in different segmental realizations in certain languages. For example, Finnish uses nominative case for NPs that denote the set of entities about which a characterizing statement is made, and uses partitive case for indefinites in episodic sentences. In Japanese, NPs of the first kind carry a topic marker.

One further argument for the ambiguity analysis when extended to other languages is that there are languages in which bare NPs do not occur in argument places reserved for kind reference, but may occur in characterizing sentences or episodic sentences. The following data are from Longobardi (2001), on Italian:
a. Elefanti di colore bianco possono creare grande curiosità. 'White-colored elephants may raise a lot of curiosity.'
b. *Elefanti di colore bianco sono estinti. 'White-colored elephants are extinct.'

To summarize, we are facing the following predicament: On the one hand, there is clear evidence that bare NPs are never interpreted just as the plural versions of indefinite NPs; otherwise, they would allow for wide scope readings, and they could not be antecedents of kind-referring reflexives or PRO. On the other, there is equally clear evidence that not all uses of bare NPs refer to kinds: They significally differ from other kind-referring NPs, and they show many similarities with indefinite NPs. The question, then, is: Are bare NPs kind referring, or are they ambiguos between a kind-referring and an indefinite reading? In the following, I will first discuss Chierchia (1998), a theory that, while selling itself as a kind-reference analysis, allows for systematic flexibility in the interpretation of NPs. I will point out a number of problems, and then propose another theory of flexible interpretation. It will turn out that bare NPs basically are neither kind-referring nor indefinites, but that they can be coerced to kind-referring or indef inite NPs. 


\section{The Theory of Chierchia (1998)}

\subsection{Ontological requirements for kind reference}

Chierchia assumes, in line of much work on the semantics of plurals and mass nouns such as Link (1983), that individuals form an atomic join semi-lattice, with a sum operation $\oplus$, a part relation $\leq$, and a set of atoms AT. Interpretations are with respect to possible worlds. The meaning of a singular count noun like $d o g$ is a property, a function that maps every world $w$ to the set of (atomic) dogs in w:

$$
\llbracket d o g \rrbracket=\operatorname{DOG},=\lambda w \lambda x[\operatorname{DOG}(\mathrm{w})(\mathrm{x})] \quad(\text { where: } \operatorname{If} \operatorname{DOG}(\mathrm{w})(\mathrm{x}), \text { then } \mathrm{x} \in \mathrm{AT}) .
$$

The meaning of a plural count noun is the transitive closure of the meaning of the singular count noun under $\oplus$, minus the atomic individuals. This ensures that $\operatorname{dogs}$ will apply to sum individuals consisting of one or more dogs.

$$
\llbracket d o g s \rrbracket=\mathrm{DOGS},=\lambda \mathrm{w} \lambda \mathrm{x}[\neg \mathrm{DOG}(\mathrm{w})(\mathrm{x}) \wedge \forall \mathrm{y}[\mathrm{y} \leq \mathrm{x} \wedge \mathrm{AT}(\mathrm{y}) \rightarrow \operatorname{DOG}(\mathrm{w})(\mathrm{y})]]
$$

Notice that DOGS is a cumulative property, that is, for any world $w$, if $\operatorname{DOGS}(w)(x)$ and DOGS(w) $(\mathrm{y})$, then DOGS(w) $(\mathrm{x} \oplus \mathrm{y})$. Mass nouns denote properties that are cumulative as well, but they also apply to atomic entities. The meaning of furniture applies to single pieces of furniture and to entities that consist of pieces of furniture.

The def inite article denotes the maximization operator $\mathrm{l}$, which, when applied to a predicate $\mathrm{P}$, returns the greatest individual in $\mathrm{P}$. If $\mathrm{P}$ doesn't have a single greatest individual, then $\mathrm{lP}$ is undefined. If a predicate $\mathrm{P}$ is cumulative, finite, and nonempty, then $\mathrm{lP}$ always exists. Hence the meaning of the dogs is defined in a world in which there are dogs, as DOGs is cumulative, whereas the meaning of the dog is defined only for those worlds in which there is a single dog, cf. (26.a,b).
a. 【the dogs $\rrbracket=\lambda \mathrm{w}[\mathrm{l}[\operatorname{DOGS}(\mathrm{w})]]$
b. 【the dog $\rrbracket=\lambda \mathrm{w}[\mathrm{l}[\mathrm{DOG}(\mathrm{w})]]$

Kinds have a hybrid nature; they are individual concepts, i.e. functions from worlds to individuals, but also members of the set of atoms. The set of kinds $\mathrm{K}$ is a proper subset of the set of atoms, AT. They are also related to properties by the down operator $^{\cap}$. Applied to a property $\underline{P}$, this operator yields the function that maps each world $w$ to the greatest element of the extension of $\underline{P}$ in $w$, provided that this is an element of the set of kinds $\mathrm{K}$ :

$$
\underline{\mathrm{P}}=\lambda \mathrm{w}[\mathrm{l} \underline{\mathrm{P}}(\mathrm{w})] \text {, if this is an element of } \mathrm{K} \text {, else undefined. }
$$

The down operator is so-called because it "brings down" the type of a property to the type of an individual concept (and, as elements of the set $\mathrm{K}$ are also entities, to an individual). This reflects the long-recognized double nature of bare NPs as referring expressions, as in Gold is a metal, and predicates, as in This ring is gold (cf. ter Meulen (1980)).

Chierchia exploits the fact that properties whose extensions do not have a greatest individual cannot be mapped to a kind. In particular, singular properties like DOG cannot be associated with a kind by the down operator, as in worlds $w$ in which there is more than one dog, $\mathrm{lDOG}(\mathrm{w})$ is not defined, cf. (28.a). In contrast, cumulative properties, like DOGS, can be associated with a kind, cf. (28.b).

\footnotetext{
a. ${ }^{\mathrm{DOG}}=\lambda \mathrm{w}[\mathrm{LDOG}(\mathrm{w})]$, undefined if there are worlds with two dogs.

b. $\mathcal{D D O G S}^{2} \lambda \mathrm{w}[\operatorname{IDOGS}(\mathrm{w})]$, if $\lambda \mathrm{w}[\operatorname{lDOGS}(\mathrm{w})] \in \mathrm{K}$
} 
There is a problem with this approach: Chierchia must allow for kinds that have no specimens in certain possible worlds for several reasons, for example, to treat extinct kinds. Hence he must allow for kinds to be partial individual concepts that are not defined for certain possible worlds; e.g. the kind $\lambda w[\mathrm{LDODO}(\mathrm{w})]$ is not defined for our world/time w. But then individual concepts like (28.a) look much more natural: They pick out, for every world that has exactly one dog, this dog. And it is unclear why the property of cumulativity should play a crucial role in determining which kind exists and which kind does not.

The down operator has as its inverse the up operator ${ }^{u}$, which maps a kind individual to the property of being a part of that individual:

If $\mathrm{k}$ is a kind individual, then $\mathrm{v}=\lambda \mathrm{w} \lambda \mathrm{x}[\mathrm{x} \leq \mathrm{k}(\mathrm{w})]$

This gives us the property of being a specimen of the kind $\mathrm{k}$, similar to Carlson's $\mathrm{R}$ relation. It includes atomic individuals and sum individuals. If $\mathrm{d}$ is the kind canis (that is, the kind of dogs), then $\cup_{\mathrm{d}}$ is the property that identifies, for each possible world, the atomic dogs and the sum individuals of dogs in this world. Notice that $\cup_{d}$, $={ }_{\text {DOGS, }}$ differs from DOGS: While DOGs only applies to sum individuals of dogs, $\cup_{\mathrm{d}}$ in addition applies to atomic dogs. For mass nouns, like FURNITURE, we have U FURNITURE $=$ FUNRNITURE, if ? FURNITURE is a kind (an element of $\mathrm{K}$ ).

\subsection{Type shifting of denotations and types of kind predications}

In order to explain the various forms of NPs used for kind reference in English and a variety of other languages, Chierchia assumes certain type shift operations. For NP denotations, Partee (1987) proposed a number of type shift rules between the recognized NP types of entity, predicate, and quantifier, like the type shift $\exists$ that maps a predicate to a quantifier, the type shift $\mathrm{l}$ that maps a predicate to an individual, or the type shift BE that maps an indefinite quantifier to a predicate. Intensional versions of these shifts are given in $(30 . a, b, c)$.

$$
\begin{array}{lll}
\text { a. } & \exists: & \mathrm{P} \Rightarrow \lambda w \lambda \mathrm{P} \exists \mathrm{x}[\mathrm{P}(\mathrm{w})(\mathrm{x}) \wedge \mathrm{P}(\mathrm{x})] \\
\text { b. } & \mathrm{l}: & \lambda \mathrm{w} \lambda \mathrm{y}[\mathrm{y} \leq \mathrm{x}] \Rightarrow \lambda \mathrm{w}[\mathrm{x}](\text { undef ined for other predicates) } \\
\text { c. } & \mathrm{BE}: & \lambda w \lambda \mathrm{P} \exists \mathrm{x}[\underline{\mathrm{P}}(\mathbf{w})(\mathrm{x}) \wedge \mathrm{P}(\mathrm{x})] \Rightarrow \underline{\mathrm{P}} \\
& & \text { or more generally, } \mathrm{Q} \Rightarrow \lambda \mathrm{w} \lambda \mathrm{x} \forall \mathrm{P}[\mathrm{Q}(\mathrm{w})(\mathrm{P}) \rightarrow \mathrm{P}(\mathrm{x})]
\end{array}
$$

Type shifts can be indicated by overt determiners. In English, the indefinite determiner $a$ indicates $\exists$, and the definite determiner the indicates 1 . But type shift can also happen without overt marking, if the linguistic context requires it, by coercion. Coercion is constrained by a blocking principle that says that if a language has overt means to express a type shift, then they have to be used. This explains some of the variation that we find in the structure of the NP (or DP) in different languages: In English, $\exists$ and $l$ cannot apply freely because of the presence of $a$ and the; however, $\exists$ can apply with plurals and mass nouns, which do not combine with $a$. Italian also has a plural indef inite determiner, the partitive article dei, as in dei cani 'dogs', hence $\exists$ cannot apply freely with plurals either. Slavic languages don't have any articles, hence $\exists$ and $i$ can apply freely. In a language that has only one type of article, like Hebrew, which only has a definite article, this article has to be used to express the corresponding type shift, whereas the other type shift is free.

Chierchia's operators can also be seen as type shifters: ${ }^{u}$ maps kind individuals to properties, $\mathrm{cf}$. (31.a), and ${ }^{\wedge}$ maps those properties that correspond to kinds to their kind individual, cf. (31.b). As far as we know, there is no language that has specialized determiners for these type shifters, hence they are not restricted by the blocking principle, and can always apply freely. 
a. $\quad \because: \quad k \Rightarrow \lambda w \lambda x[x \leq k(w)]$, if $k \in K$, else undefined.

b. $\cap: \underline{P} \Rightarrow \lambda w[l \underline{P}(w)]$, if $\lambda w[l \underline{P}(w)] \in K$, else undefined.

In addition to the presence or absence of overt determiners, languages also differ in the way how arguments of verbal predicates can be filled, and how nominals can be interpreted. Chierchia captures this with two binary features: NP[ \pm arg] relates to the variation whether nouns can or cannot be arguments (that is, refer to entities), and NP[ \pm pred] to the variation whether nouns can or cannot be predicates. For example, in Chinese nouns denote kind entities and hence can be arguments, but they cannot directly be predicates; in Romance the situation is reversed; and in English mass nouns denote kind entities whereas bare plurals basically denote predicates. This feature system strikes me as something that should be eliminated if we can capture its intended effects by type shifts, overt articles and the blocking principle.

Let us now discuss various types of predications within Chierchia's theory, for English. We start with regular kind predications that involve predicates that select for kinds. Chierchia assumes that mass nouns directly refer to kinds, hence no shift is necessary, cf. (32.a). Count nouns basically denote predicates, but they can refer to kinds by free type shift with the down operator, which requires a plural form, cf. $(32 . b, c)$. Recall that kind individuals are individual concepts that are also atomic individuals, hence they can fill the argument slots of predicates.
a. Gold is a metal.
$\lambda w[M E T A L(w)(A U R E U M)]$
b. Dodos are extinct.
$\lambda w[\operatorname{EXTINCT}(w)($ DODOS)]
c. *Dodo is extinct.
$* \lambda w\left[\operatorname{EXTINCT}(w)\left({ }^{D} D O D O\right)\right.$, as ${ }^{2} \mathrm{DODO}$ is undefined.

Characterizing statements need a restrictor for their quantificational operator. It can be provided by kind-denoting NPs if they are shifted to their corresponding property by the up operator ${ }^{\smile}$. Chierchia assumes analyses like (33.a) for mass nouns and (33.b) for count nouns; notice that the bare plural is shifted back to the property use.
a. Gold is shiny.
$\lambda w\left[\mathrm{GEN}(\mathrm{w})\left({ }_{\mathrm{U}} \mathrm{AUREUM}\right)\left(\mathrm{IS} \_\mathrm{SHINY}\right)\right]$
b. Lions have a mane.

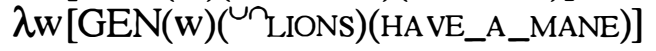

By this analysis, the kind-referring analysis of bare NPs is made compatible with the view that characterizing statements have a quantificational structure. But there are is a problem that I would like to point out: It is not clear what prevents simpler derivations like (34.a) for sentences with bare plurals. And if this is possible, we cannot prevent the derivation of sentences with bare singular count nouns, like (34.b)
a. Lions have a mane.
$\lambda w[G E N(w)(L I O N S)$ (HAVE_A_MANE)]
b. *Lion has a mane.
$\lambda w\left[G E N(w)(L I O N)\left(H A V E \_A \_M A N E\right)\right]$

\subsection{Derived Kind Predications}

Let us now consider NPs in non-generic sentences. Chierchia follows Carlson in assuming that bare NPs in such sentences, at least at some stage in the derivation, denote kinds. In contrast to Carlson's original theory, the introduction of specimens is not accomplished by an existential quantifier inherent in the meaning of the verbal predicate, but by the derived kind predication rule (the DKP rule, in short), cf. (35). An episodic sentence with a bare plural NP is interpreted as in (36).

DKP rule: If the verbal predicate $\mathbf{P}$ applies to objects, and $\mathrm{k}$ denotes a kind, then $\lambda w[P(w)(k)] \Leftrightarrow \lambda w \exists x\left[{ }^{\complement} k(w)(x) \wedge P(w)(x)\right]$ 

a. Dogs are barking.
b. $* \lambda w$ w BARKING(w)( DOGs)], due to sortal mismatch.
c. By DKP rule: $\lambda w \exists x[\sim \operatorname{DOGS}(w)(x) \wedge \operatorname{BARKING}(w)(x)]$ $=\lambda w \exists x[x \leq \operatorname{lDOGS}(w) \wedge \operatorname{BARKING}(w)(x)]$

By the DKP rule bare NPs have narrow scope, if we assume that it is triggered as late as possible in the derivation - that is, when an argument position of a predicate that selects for an object is to be filled with a kind. Consider (37), with a logical form in which dogs is LF-moved, thus suggesting a wide-scope interpretation, as in (37.a), where I use conventions of Heim \& Kratzer (1998). In the interpretation, cf. (37.b), the basic meaning of the subject, DOGS, will be shifted to DoGs, in order to satisfy the type requirements of the verbal predicate. After applying $\lambda \mathrm{x}[\neg[\operatorname{SEE}(\mathrm{w})(\mathrm{x})(\mathrm{J})]]$ to it, we get the representation in (37.c). This is the point where the sortal conflict between the requirement of the predicate and the nature of the argument matters. The DKP rule for the object position will apply, resulting in the meaning (37.d), which is equivalent to (37.e).

John didn't see dogs.
a. LF: [dogs $\lambda 1\left[\right.$ John didn't see $\left.t_{1}\right]$ ]
b. interpretation: $\lambda \mathrm{w}\left[\lambda \mathrm{x}[\neg[\mathrm{SEE}(\mathrm{w})(\mathrm{x})(\mathrm{JOHN})]]\left({ }^{\mathrm{DOOGS}}\right)\right]$
(after type shift DOGS $\Rightarrow$ DOGS, to satisfy type requirement)
c: after application: $\lambda w \neg[\operatorname{SEE}(w)(\mathcal{D O G S})(\mathrm{JOHN})]$
d. after DKP: $\lambda w \neg \exists x\left[\sim \sim^{-D O G S}(w)(x) \wedge \operatorname{SEE}(w)(x)(J O H N)\right]$
e. $=\lambda \mathrm{w} \neg \exists x[[\operatorname{DOG}(\mathrm{w})(\mathrm{x}) \vee \operatorname{DOPS}(\mathrm{w})(\mathrm{x})] \wedge \operatorname{SEE}(\mathrm{w})(\mathrm{x})(\mathrm{JOHN})]$

Contrast this with indef inite singulars like $a$ dog. The logical form in which $a$ dog is moved over negation, cf. (38.a), will result in an interpretation in which the indefinite has wide scope, cf. $(38 . b, c)$.

John didn't see a dog.
a. LF: [a dog $\lambda 1$ [John didn't see $t_{1}$ ]]
b. interpretation: $\lambda w[\lambda P \exists x[D O G(w)(x) \wedge P(x)](\lambda x[\neg[\operatorname{SEE}(w)(x)(J)])]$
c. after application: $=\lambda \mathrm{w} \exists \mathrm{x}[\operatorname{DOG}(\mathrm{w})(\mathrm{x}) \wedge \neg[\operatorname{SEE}(\mathrm{w})(\mathrm{x})(\mathrm{J})]]$

The DKP rule is problematic on two counts: First, it is not couched in the general format of Chierchia's account, which makes heavy use of type shifts. This can be remedied; the semantic changes involved in it are as follows:

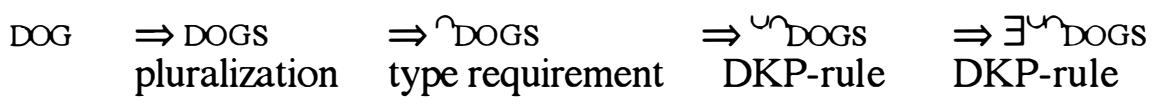

But now the second problem appears: The type shifts involved in derived kind predications are overly complex, and it is difficult to see how they can be motivated by general principles of type shifting. The first shift in (39) is explicitly triggered by pluralization. The second shift, to DoGS, is not immediately motivated, because the resulting structure, BARKING(W)( DOGS), could not be interpreted due to a sortal conflict: The predicate BARKING(w) expects an ordinary object, not a kind. Hence DoGS has to be modified by the DKP rule, which combines two type shifts: The first one,

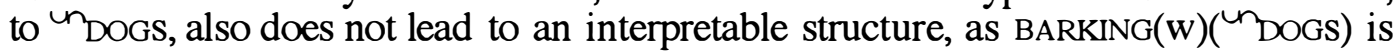
still not well-formed. Only after shifting the property unDGs to a quantifier by $\exists$ do

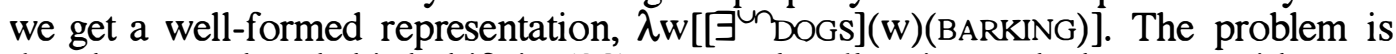
that the second and third shift in (39) are not locally triggered: they are neither enforced by an overt operator, nor do they lead to an interpretable structure. 
We may perhaps entertain type-shift systems in which type shifts do not have to lead to locally interpretable structures, provided that the overall result is interpretable. Still, we would like to assume that in general, simpler shifts are preferred over more complex ones. Now, there is a considerably simpler sequence of type shifts that in addition leads to locally interpretable structures, and can account for the reading of sentences like Dogs are barking. It is given in (40).

$$
\text { DOG } \begin{array}{ll}
\Rightarrow \text { DOGS } & \Rightarrow \exists \text { DOGs } \\
\text { pluralization } & \text { type requirement }
\end{array}
$$

Consider (41) as an example. As before, the straight interpretation (41.a) does not work out, this time due to a type clash: The verbal predicate expects an entity, but $\operatorname{DOGS}(w)$ is a set. The remedy is to shift the meaning of DOGs to a quantifier, using $\exists$, which has the consequence that the verbal predicate will become an argument, cf. (41.b). This is an interpretable structure, and can be simplified to (41.d).

Dogs are barking.

a. $* \lambda w[$ BE_BARKING $(w)(\operatorname{DOGS}(w))]$, due to type clash.

b. $\lambda w\left[[\exists(D O G S)](w)\left(B E \_B A R K I N G(w)\right)\right]$, after type shift DOGS $\Rightarrow \exists$ DOGS

c. $=\lambda w\left[\lambda \mathrm{P}^{\prime} \exists \mathrm{x}\left[\operatorname{DOGS}(\mathrm{w})(\mathrm{x}) \wedge \mathrm{P}^{\prime}(\mathrm{x})\right](\operatorname{BARKING}(\mathrm{w}))\right]$

$\mathrm{d} .=\lambda \mathrm{w} \exists \mathrm{x}[\operatorname{DOGS}(\mathrm{w})(\mathrm{x}) \wedge \operatorname{BARKING}(\mathrm{w})]$

Chierchia is aware of the possible derivation (41), but he considers the DKP derivation (36) preferable because the shift by the down operator, $\cap$, which is responsible for the detour that this derivation takes, is more meaning preserving that the existential shift by $\exists$. The reason is that $\exists$ adds existential import; it claims the existence of an entity of a particular type. But notice that a derivation like (36) requires existential import at the end of the day anyway, by the DKP rule.

Chierchia assumes that the type shifts sequence (40) applies in cases in which a nominal predicate does not correspond to a kind like parts of that machine or persons in this building, cases already identified by Carlson (1977). In contrast to nouns that correspond to kinds, we find wide-scope readings of bare NPs in such cases. Section 4.2 will present another explaination of the behavior of such NPs.

\subsection{Singular definite kind terms}

Chierchia also offers an interesting proposal for singular definite kind terms as in the dodo is extinct, partly following Dayal (1992), cf. also Dayal (2002). Definite generic NPs refer to singular kinds that pick out, for each world, a group individual, a special type of atomic individual. Group individuals were proposed by Link (1983) and Landman (1989) as the referents of collective NPs like the Jones family that are distinct from sum individuals, like the individuals picked out by the members of the Jones family. Even though group individuals are related to members, they are atomic, as argued for in Barker (1992). In particular, collective NPs do not allow predicates that explicitly refer to the number of its members, in contrast to sum individuals, $\mathrm{cf}$. (42). They share this property with singular kind NPs, in contrast to regular kind NPs, cf. (43), as observed in Kleiber (1989).

(42) a. *The Jones family is numerous.

b. The members of the Jones family are numerous.

a. *The tiger is numerous.

b. Tigers are numerous. 
Chierchia proposes a "massification" operator MASS that applies to the meaning of singular count nouns, like DOG, so that MASS(DOG(w)) refers to atomic dogs and sum individuals of dogs in $\mathrm{w}$. There is also a group-formation operator $\mathrm{g}$ that maps plural individuals to atomic groups that have the atomic parts of the plural individual as their members. The meaning of definite generic the dodo is illustrated in (44).

$$
\llbracket \text { the dodo }]=\lambda \mathrm{w}[\mathrm{g}(\mathrm{lMASS}(\mathrm{DODO}(\mathrm{w}))]
$$

We now can account for differences with numerous predications. (45.a) says that the sum individual of all dodos in the world $w$ has the property of being numerous in $\mathrm{w}$, which is fine. (45.b) says that the group individual representing all dodos in the world w is numerous in w, which is not good, as this individual is an atom.

$$
\begin{aligned}
\text { a. Dodos are numerous. } & =\lambda w[\operatorname{NUM}(w)(\operatorname{DODOS}(w)) \\
& =\lambda w[\operatorname{NUM}(w)(1[\operatorname{DODOS}(w)])] \\
\text { b. } * \text { The dodo is numerous. } & =\lambda w\left[\operatorname { N U M } ( w ) \left(\lambda w^{\prime}\left[g\left(\operatorname{lMASS}\left(\operatorname{DODO}^{\prime}\left(w^{\prime}\right)\right)\right](w)\right]\right.\right. \\
& =\lambda w\left[\operatorname{NUM}(w)\left(g\left(\operatorname{lMASS}\left(\operatorname{DODO}\left(\mathrm{w}^{\prime}\right)\right)\right)\right)\right]
\end{aligned}
$$

We have already seen that singular kinds can also be the object of regular kind predications, as in example (46.a), which now is analyzed as in (46.b).

$$
\text { a. The dodo is extinct. b. } \lambda w[\operatorname{EXTINCT}(w)(\lambda w[g(\operatorname{lMASS}(\operatorname{DODO}(w)))])]
$$

For this analysis to work, we must assume that not only regular kinds, like ?DODOs, are elements of the subset $\mathrm{K}$ of atomic individuals, but also singular kinds like $\lambda w[g(\operatorname{lMASS}(\operatorname{DODO}(\mathrm{w})))]$. This proliferation of kind individuals should be avoided if we just consider regular kind predications (but see Dayal 2002 for other uses).

If this analysis is couched in a type-shift framework, it is unclear what could trigger the shift to the required meaning for expressions like the dodo. If the basic meaning of the dodo is $\mathrm{lDODO}$, then a shift to the meaning $\lambda \mathrm{w}[\mathrm{g}(\mathrm{lMASS}(\mathrm{DODO}(\mathrm{w})))]$ would be fairly complex due to the presence of the MASS operator. An alternative is that the definite article the, in addition to its ordinary meaning $\mathrm{l}$, also has a meaning $\mathrm{l}^{*}=\lambda \mathrm{w} \lambda \mathrm{P}[\mathrm{g}(\mathrm{lMASS}(\mathrm{P}))]$ that, when applied to a singular count noun like dodo, yields the required meaning that denotes a singular kind. But then we should expect that some languages lexicalize $\imath^{*}$, yet a generic definite article has not been found.

Consider now singular definite kind-referring NPs in characterizing statements, which are analyzed by assuming that the restrictor of the quantifier is specified by the members of the group denoted by the NP, as in (47). Here, $\leq_{m}$ is the membership relation. The sentence says that generally, members of the group that corresponds to the sum of dodos have a black beak.

The dodo has a black beak.

$\lambda w\left[\operatorname{GEN}(w)\left(\lambda w \lambda x\left[x \leq_{m} g(\operatorname{MASS}(D O G(w)))\right]\right)\left(H A S \_A \_B L A C K \_B E A K\right)\right]$

In a type-shift framework, the introduction of members should be enforced by a general type shifter ${ }^{u m}$ that is like the up operator ${ }^{\smile}$, except that it makes use of the member relation $\leq_{\mathrm{m}}$ instead of the part relation $\leq$

$$
\mathrm{um}_{\mathrm{s}}=\lambda \mathrm{w} \lambda \mathrm{x}\left[\mathrm{x} \leq_{\mathrm{m}} \mathrm{s}(\mathrm{w})\right] \text {, if } \mathrm{s} \text { is a singular kind, else undefined. }
$$

It is unclear, however, how the restrictions for definite generic NPs in characterizing statements should be accounted for, which were illustrated in (1.b) and (4.a). It appears that we have to distinguish between two types of characterizing statements: Those that make inductive generalizations, and those that express rules or regu- 
lations, including definitions, cf. Carlson (1995), Cohen (2002). While indefinite singular NPs and probably also bare singular NPs occur in either type, definite generic NPs do not occur in the rule or regulation type:
a. A gentleman opens doors for ladies.
b. Gentlemen open doors for ladies.
c. *The gentleman opens doors for ladies.

Consider now episodic sentences like (50). There are two interpretations that are theoretically possible: (50.a), saying that the group individual representing all the dogs in $w$ is barking in w. Or (50.b): The original representation (i) is not interpretable, but a rule similar to the DKP rule, using the type shift ${ }^{\mathrm{m}}$ and $\exists$, cf. (ii), leads to an (iii) which is true in $w$ if one or more dogs in $w$ are barking in $w$.

The dog is barking outside.
a. $\lambda w\left[\operatorname{BARKING}(w)\left(\lambda w^{\prime}\left[g\left(\operatorname{lMASS}\left(\operatorname{DOG}\left(w^{\prime}\right)\right)\right)\right](w)\right)\right]$ $=\lambda \mathrm{w}[\mathrm{BARKING}(\mathrm{w})(\mathrm{g}(\mathrm{lMASS}(\mathrm{DOG}(\mathrm{w}))))]$
b. i. $* \lambda w\left[B A R K I N G(w)\left(\lambda w^{\prime}\left[g\left(\operatorname{lMASS}\left(\operatorname{DOG}\left(w^{\prime}\right)\right)\right)\right]\right)\right]$
ii. $\lambda w\left[\exists\left[{ }^{\prime} \lambda w^{\prime}\left[g\left(\operatorname{lMASS}\left(\operatorname{DOG}\left(w^{\prime}\right)\right)\right)\right]\right](w)(B A R K I N G(w))\right]$
iii. $=\lambda \mathrm{w} \exists \mathrm{x}\left[\mathrm{x} \leq_{\mathrm{m}} \mathrm{g}(\operatorname{lMASS}(\operatorname{DOG}(\mathrm{w})) \wedge \operatorname{BARKING}(\mathrm{w})(\mathrm{x})]\right.$

Interpretation (50.a) is certainly not natural to express that all the dogs are barking, perhaps because there are simpler ways to express this. But this type of interpretation might be suitable to express certain kind predications discussed in Krifka et. al. (1995). It is what is required for collective predications as in The American customer bought 74.000 BMWs last year. It is also plausible for avantgarde interpretations as in The rat reached Australia in 1770, as we can attribute important properties of group members to the group, cf. The Rothschild family established a banking house in Paris in 1812. Interpretation (50.b) is impossible altogether, thus posing a problem for this approach.

\section{Elements of a revised theory for bare NPs}

Let me now discuss an alternative to Chierchia (1998) that overcomes many of the problems mentioned above, while remaining quite close in spirit to this work. In particular, it will work with the assumption that NP denotations can be type shifted, and that free type shifts are blocked by the existence of overt determiners.

In the following, I will pay closer attention to the compositional derivation of expressions. Binary branching constituents $[\alpha \beta]$ are interpreted as follows:

$$
\begin{aligned}
& \llbracket[\alpha \beta]] \\
& \text { a. }=\lambda w[\{\llbracket \alpha \rrbracket(w), \llbracket \beta \rrbracket(w)\}] \\
& \text { b. }=\lambda w[\llbracket \alpha \rrbracket(w)(\llbracket \beta \rrbracket(w))] \text { or } \lambda w[\llbracket \beta \rrbracket(w)(\llbracket \alpha \rrbracket(w))] \text {, whatever well formed. } \\
& \text { c. if b fails: }=\lambda w[\{\operatorname{TS}(\llbracket \alpha \rrbracket)(w), \llbracket \beta \rrbracket(w)\}] \text { or } \lambda w[\{\llbracket \alpha \rrbracket(w), \operatorname{TS}(\llbracket \beta \rrbracket)(w)\}] \text {, } \\
& \text { where TS is a suitable type shift operation. }
\end{aligned}
$$

(51.a) says that the resulting meaning is always an intension, a function from possible worlds $w$, which is a function of the extensions of the constituents $\alpha$ and $\beta$. This is like in Montague (1973), except that quantification over possible worlds is explicit. The set denotation employed here indicates that it is still undetermined how these meanings are to be combined. (51.b) states that either the extension of $\alpha$ is to be applied to the extension of $\beta$, or vice versa. If this fails, (51.c) says that things can 
be rescued by a suitable type shift operation on one of the meanings of the subconstituents. The set of type shifters should include Partee's and Chierchia's operators.

\subsection{The nature of count nouns and plural marking}

Recall how Chierchia's theory explains the ungrammaticality of ${ }^{*}$ Dog is barking. The meaning of $d o g$ is a property, and properties cannot fill the argument slots of verbal predicates due to a type mismatch. This mismatch cannot be resolved by the down operator ${ }^{n}$, as this requires a cumulative property. It cannot be resolved by $\exists$ or $l$ either, as these shifts are blocked by the overt determiners $a$ and the. In languages that lack articles, as in Slavic languages, type shifts by $\exists$ and $\mathrm{t}$ are possible; also in languages like Chinese, in which nouns basically denote kinds.

The problems with this account have been discussed in section 3.3 on the DKP rule above. There is a quite different line of explanation that has been proposed in Krifka (1989), and in Krifka (1995), a comparison between English and Chinese. The basic idea is that count nouns have a number argument that can be specified by a number word; mass nouns lack such an argument. This idea is exemplified in $(52 . a, b)$. A formula like $\operatorname{DOG}(\mathrm{w})(\mathrm{n})(\mathrm{x})$ says that in the world $\mathrm{w}$, the individual $\mathrm{x}$ consists of $\mathrm{n}$ dogs.

$$
\begin{array}{ll}
\text { a. }[\text { dog }]=\lambda w \lambda n \lambda x[\operatorname{DOG}(\mathrm{w})(\mathrm{n})(\mathrm{x})],=\mathrm{DOG}, \text { type }\langle\mathrm{s},\langle\mathrm{n},\langle\mathrm{e}, \mathrm{t}\rangle\rangle\rangle \\
\mathrm{b} .[\text { gold } \rrbracket=\lambda \mathrm{w} \lambda \mathrm{x}[\mathrm{GOLD}(\mathrm{w})(\mathrm{x})],=\mathrm{GOLD}, \text { type }\langle\mathrm{s},\langle\mathrm{e}, \mathrm{t}\rangle\rangle
\end{array}
$$

More specifically, count nouns denote extensive measure functions, like gallon or mile: They relate a given entity to maximally one number, cf. (53.a), and they are additive, cf. (53.b), illustrated for $d o g$. Additivity requires that if $\mathrm{x}$ is a sum individual consisting of $\mathrm{n}$ dogs, and $\mathrm{y}$ is a sum individual consisting of $\mathrm{m}$ dogs, and $\mathrm{x}$ and $\mathrm{y}$ do not overlap, then the sum $\mathrm{x} \bigoplus \mathrm{y}$ is a sum individual consisting of $\mathrm{n}+\mathrm{m}$ dogs.
a. If $\operatorname{DOG}(\mathrm{w})(\mathrm{n})(\mathrm{x})$ and $\operatorname{DOG}(\mathrm{w})(\mathrm{m})(\mathrm{x})$, then $\mathrm{n}=\mathrm{m}$.
b. If $\operatorname{DOG}(w)(n)(x), \operatorname{DOG}(w)(m)(y)$ and $x, y$ do not overlap, $\neg \exists z[z \leq x \wedge z \leq y])$, then $\mathrm{DOG}(\mathrm{w})(\mathrm{n}+\mathrm{m})(\mathrm{x} \oplus \mathrm{y})$.

The number arguments can be filled by number words, as in (54.a,b):

$$
\begin{aligned}
\text { a. } & \llbracket \text { one dog } \rrbracket \\
& =\lambda \mathrm{w}[\llbracket \text { dog }](\mathrm{w})(\llbracket \text { one } \rrbracket(\mathrm{w}))] \\
& =\lambda \mathrm{w}[\lambda \mathrm{n} \lambda \mathrm{x}[\mathrm{DOG}(\mathrm{w})(\mathrm{n})(\mathrm{x})](1)] \\
& =\lambda \mathrm{w} \lambda \mathrm{x}[\operatorname{DOG}(\mathrm{w})(1)(\mathrm{x})]
\end{aligned}
$$
b. 【two dogs $\rrbracket$$$
=\lambda \mathrm{w}[\llbracket \operatorname{dog} \rrbracket(\mathrm{w})(\llbracket t w o \rrbracket(\mathrm{w}))]
$$$$
=\lambda \mathrm{w}[\lambda \mathrm{n} \lambda \mathrm{x}[\operatorname{DOG}(\mathrm{w})(\mathrm{n})(\mathrm{x})](2)]
$$$$
=\lambda w \lambda x[\operatorname{DOG}(w)(2)(x)]
$$

The difference in the grammatical number of the noun is a matter of syntactic agreement with the number word. Evidence for this comes from two facts. First, decimal fractions always trigger plural agreement, even for the number word one point zero, which presumably has the same meaning as one, as $1.0=1$ is a mathematical fact. (There are differences in admitted vagueness, cf. Krifka (2002)).

American households have, on average, zero point seven $\{$ cats / $*$ cat $\}$ and one point zero $\{$ dogs $/ * \operatorname{dog}\}$.

Secondly, there are many languages that have distinct plural forms for count nouns but lack agreement with number words. See (56) for Hungarian examples. 

a. egy kutya b. one dog 'one dog'
két kutya c. kutyák two dog dog.PL 'two dogs' 'dogs'
d. a kutya the dog the dog.PL
e. a kutyák 'the dogs'

NPs consisting of count nouns with a specified number argument denote predicates that are quantized. That is, if the NP seven cats refers to an entity $\mathrm{x}$, then it cannot apply to proper parts of $\mathrm{x}$, or to individuals that have $\mathrm{x}$ as a proper part. This follows from the fact that count nouns express measure functions. With mass nouns, quantized predicates can be built with explicit measure functions, such as gallon:

$$
\begin{aligned}
& \llbracket \text { three gallons of milk } \rrbracket \\
& =\lambda \mathrm{w} \lambda \mathrm{x}[\llbracket \text { three gallons } \rrbracket(\mathrm{w})(\mathrm{x}) \wedge \llbracket \text { milk }](\mathrm{w})(\mathrm{x})] \\
& =\lambda \mathrm{w} \lambda \mathrm{x}[\mathrm{GALLON}(\mathrm{w})(3)(\mathrm{x}) \wedge \mathrm{MLK}(\mathrm{w})(\mathrm{x})]
\end{aligned}
$$

Classifier languages, like Chinese, don't have count nouns and rely on measure constructions for expressing quantization in general. The classifier is a measure function that may be interpreted either as a measure of the number of atoms of an entity, cf. (58.a), or as a measure function that is characteristic for the meaning of the head noun, called a "Natural Unit" (NU) in Krifka (1995), cf. (58.b).

$$
\begin{aligned}
& \text { san ben shu 'three CL book' } \\
& \text { a. } \lambda w \lambda x[\operatorname{ATOM}(w)(3)(x) \wedge \text { BOOK }(w)(x)] \\
& \text { b. } \lambda w \lambda x[[N U(B O O K)](w)(3)(x) \wedge \operatorname{BOOK}(w)(x)]
\end{aligned}
$$

The difference between count noun constructions like three books, and classifier constructions like san ben shu, then is the following: In count noun constructions, the unit of measurement is part of the lexical meaning of the noun; in classifier constructions, the unit of measurement is expressed by a separate lexical element.

In addition to the agreement plural which shows up in forms like two dogs, English also has a semantic plural that is responsible for bare plural NPs. This is the plural we also find in Hungarian. As the number argument is not filled overtly, plural morphology does the job, creating a property. This number argument can either be specified as greater than 1, cf. (59.a), or be left unspecified, as in (59.b).

$$
\begin{aligned}
& \llbracket \text { dog-s } \rrbracket=\lambda \mathrm{w}[\llbracket-s \rrbracket(\mathrm{w})(\llbracket \operatorname{dog} \rrbracket(\mathrm{w}))] \\
& \mathrm{a} .=\lambda \mathrm{w}[\lambda \mathrm{R} \lambda \times \exists \mathrm{n}>1[\mathrm{R}(\mathrm{n})(\mathrm{x})](\mathrm{DOG}(\mathrm{w}))],=\lambda \mathrm{w} \lambda \times \exists \mathrm{n}>1[\mathrm{DOG}(\mathrm{w})(\mathrm{n})(\mathrm{x})] \\
& \mathrm{b} .=\lambda \mathrm{w}[\lambda \mathrm{R} \lambda \mathrm{x} \exists \mathrm{n}[\mathrm{R}(\mathrm{n})(\mathrm{x})](\mathrm{DOG}(\mathrm{w}))],=\lambda \mathrm{w} \lambda \mathrm{x} \exists \mathrm{n}[\operatorname{DOG}(\mathrm{w})(\mathrm{n})(\mathrm{x})]
\end{aligned}
$$

There is ample evidence that the latter version is right. For example, a question like Do you have dogs? can be answered by Yes, one, but not by No, only one. This contrasts with questions like Do you have more than one dog?, which can be answered by No, only one. Also, notice that John doesn't have dogs is false if John has one dog; again, John doesn't have more than one dog is true in this situation. Also, If Mary has cats, then John cannot stay with her, as he is allergic entails that even if Mary just has one cat, John cannot stay with her, in contrast to If Mary has more than one cat, John cannot stay with her. True, a person that points to one dog and says See, there are dogs! would have expressed something that is true. However, the oddness of this statement can be traced back to the fact that there is a more specific expression, and one that is about equally complex, namely $a \mathrm{dog}$.

Other languages may have, in addition to the semantic plural in (59), a semantic singular that specifies the number argument of the NP with the number 1 . For example, in Slavic languages like Czech we find bare singulars and bare plurals, cf. (60.a,b). I assume that these languages have a singular operator sG, cf. (61), where $\mathrm{SG}$ operates on the noun stem $p s$, resulting in the singular form pes. 
(60)

a. štekal pes. barked dog 'A dog was barking.' b. Štekal-i psi.

barked-PL dogs

'Dogs were barking.'

$$
\begin{aligned}
& \llbracket p e s \rrbracket=\llbracket p s-\mathrm{sG} \rrbracket=\lambda \mathrm{w}[\llbracket \mathrm{sG} \rrbracket(\mathrm{w})(\llbracket p s \rrbracket(\mathrm{w}))] \\
& =\lambda \mathrm{w}[\lambda \mathrm{R} \lambda \mathrm{x}[\mathrm{R}(1)(\mathrm{x})](\operatorname{DOG}(\mathrm{w}))],=\lambda \mathrm{w} \lambda \mathrm{x}[\operatorname{DOG}(\mathrm{w})(1)(\mathrm{x})]
\end{aligned}
$$

Following the observation of Dayal (2002) cited in (19), there might be additional meaning components that come with bare singulars, in particular uniqueness presuppositions with respect to a given situation. This would not be too surprising, as bare singulars are semantically more specific than bare plurals. Condoravdi (1992) has pointed out a similar effect with certain uses of bare plurals as in (62), where students refers to the students of the campus.

A serial killer haunted the campus. Students were aware of the danger.

Such additional meaning components arise when the bare NP is in topic position, cf. section 4.4 for the relevance of information structure.

Let me summarize this section. Under the theory developed here, singular count nouns like $d o g$ differ in semantic type from plural count nouns like dogs, mass nouns like milk, or nouns with explicit number words like one dog or two dogs: Singular count nouns are functions from numbers to predicates, the other expressions are predicates. This explains the puzzle we set out with, why singular count nouns cannot occur as arguments. Singular count nouns are not of the proper type, the type of predicates. No recourse to a restriction of kind formation to cumulative properties is necessary.

\subsection{The articles, and an explanation of narrow-scope phenomena}

Let us turn to the treatment of the articles. The definite article the can be combined with singular count nouns, as in the dog, with mass nouns, as in the milk, with plural nouns, as in the dogs, and with nouns whose number argument is filled by a number word, as in the three dogs. As the type of singular count nouns differs from the rest, we assume two versions of the definite article: One that combines with predicates, cf. (63), and another one that combines with number relations, cf. (64).

$$
\begin{aligned}
& \text { a. 【the }=\lambda w \lambda \mathrm{P}[\mathrm{lP}] \\
& \text { b. 【the dogs } \rrbracket=\lambda \mathrm{w}[\llbracket \text { the } \rrbracket(\mathrm{w})(\llbracket \text { dogs } \rrbracket(\mathrm{w}))] \\
& =\lambda \mathrm{w}[\lambda \mathrm{P}[\mathrm{lP}](\lambda \mathrm{x} \exists \mathrm{n}[\mathrm{DOG}(\mathrm{w})(\mathrm{n})(\mathrm{x})])] \\
& =\lambda \mathrm{w}[\mathrm{\imath} \lambda \mathrm{x} \exists \mathrm{n}[\mathrm{DOG}(\mathrm{w})(\mathrm{n})(\mathrm{x})]] \\
& \text { c. } \llbracket \text { the }[\text { three dogs }] \rrbracket=\lambda \mathrm{w}[\mathrm{l}[\operatorname{DOG}(\mathrm{w})(3)]] \\
& \text { a. 【the }=\lambda \mathrm{w} \lambda \mathrm{R}[\mathrm{lR}(1)] \\
& \text { b. 【the dog \= }=\lambda \mathrm{w}[\llbracket \text { the }](\mathrm{w})(\llbracket \operatorname{dog} \rrbracket(\mathrm{w}))] \\
& =\lambda \mathrm{w}[\lambda \mathrm{R}[\mathrm{iR}(1)](\mathrm{DOG}(\mathrm{w}))] \\
& =\lambda \mathrm{w}[\mathrm{1} \lambda \mathrm{x}[\operatorname{DOG}(\mathrm{w})(1)]]
\end{aligned}
$$

(63.b) is defined for worlds in which there are dogs, (63.c) is defined for worlds in which there are exactly three dogs, and (64.b) is defined for wolds in which there is exactly one dog. A unified analysis of the definite article may be possible if we assume that in cases the number word is not specified, the argument slot is filled by 1 . There is independent evidence for such a default rule: Cheng \& Sybesma (1999) report that in Cantonese, the lack of specification of a number word in a classifier construction is interpreted by 1 . I leave it for future research to investigate this op- 
tion. - As an example for the derivation of a sentence meaning, consider (65); it maps worlds $w$ to truth if the single dog in $w$ is barking in $w$, to falsity if the single dog in $w$ is not barking in $w$, and is undefined if there is no dog or more than one dog.

$$
\begin{aligned}
& \llbracket[[\text { the dog }][\text { is barking }]] \rrbracket \\
& =\lambda \mathrm{w}[\llbracket \text { is barking }](\mathrm{w})(\llbracket \text { the dog } \rrbracket(\mathrm{w}))] \\
& =\lambda \mathrm{w}\left[\mathrm{BE} \_\mathrm{BARKING}(\mathrm{w})(\mathrm{l} \lambda \mathrm{x}[\mathrm{DOG}(\mathrm{w})(1)])\right]
\end{aligned}
$$

As for the indefinite article $a$, the simplest analysis might be that it is a variant of the number word one, meaning ' 1 '. After all, indefinite articles generally develop from the number word 'one', and of ten still are homophonous with it. The only difference is that one, as a number word, is pragmatically related to alternative number words, which can lead to scalar implicatures, whereas $a$, as an article, is pragmatically related to the definite article. This leads to different kinds of implicatures: John saw one dog implicates that John didn't see more than one, and John saw a dog implicates that the dog is not unique or salient.

However, $a$ differs in another respect from number words: Whereas constructions like the one $d o g$ are fine, * the a dog isn't. While we can attribute this to an incompatibility of the implicatures of the and $a$, we also can rule it out syntactically, by saying that the and $a$ occupy the same syntactic slot, which is different from the one that number words occupy in constructions like the one dog. Following the DP analysis of nominal expressions, as initiated by Abney (1987), we assume syntactic structures like (66):
a. $\left[{ }_{\mathrm{DP}}\right.$ the $\left[{ }_{\mathrm{NP}}\right.$ one $\left[{ }_{\mathrm{N}}\right.$ dog $\left.\left.]\right]\right]$
b. $\left[_{\mathrm{DP}}\right.$ the $\left[_{\mathrm{NP}}\right.$ two $\left[{ }_{\mathrm{N}}\right.$ dogs $\left.\left.]\right]\right]$
c. $\left[_{\mathrm{DP}}\right.$ the $\left[{ }_{\mathrm{NP}}[\mathrm{N}\right.$ milk $\left.\left.]\right]\right]$
d. $\left[{ }_{D P}\right.$ the $\left[{ }_{N P}-\left[{ }_{N}\right.\right.$ dog $\left.\left.]\right]\right]$
e. $\left[{ }_{\mathrm{DP}} a\left[\mathrm{NP}-\left[{ }_{\mathrm{N}} d o g\right]\right]\right]$

Articles, and other true quantifiers like every, all, most and no, form the head of the DP, whereas number words are specifiers of count nouns. They are licensed there because they fill the number slot. Singular determiners like singular the, the indefinite article $a$, but also quantifiers like every or singular no, do double duty: they contribute their quantifier or determiner meaning and satisfy the number argument of the count noun by 1 . In particular, the meaning of the indefinite article can be given as in (67); see (68) for an example derivation of a sentence.

$$
\begin{array}{ll}
\text { a. } \llbracket a \rrbracket & =\lambda w \lambda R \lambda \mathrm{P} \exists \mathrm{x}[\mathrm{R}(1)(\mathrm{x}) \wedge \mathrm{P}(\mathrm{x})] \\
\text { b. } \llbracket a d o g \rrbracket & =\lambda \mathrm{w}[\llbracket a](\mathrm{w})(\llbracket d o g \rrbracket(\mathrm{w}))] \\
& =\lambda \mathrm{w}[\lambda \mathrm{R} \lambda \mathrm{P} \exists \mathrm{x}[\mathrm{R}(1)(\mathrm{x}) \wedge \mathrm{P}(\mathrm{x})](\mathrm{DOG}(\mathrm{w}))] \\
& =\lambda \mathrm{w} \lambda \mathrm{P} \exists \mathrm{x}[\operatorname{DOG}(\mathrm{w})(1)(\mathrm{x}) \wedge \mathrm{P}(\mathrm{x})]
\end{array}
$$

$$
\begin{aligned}
& \llbracket\left[\left[{ }_{\mathrm{DP}} \text { a dog }\right][\text { is barking }]\right] \rrbracket \\
& =\lambda \mathrm{w}[\llbracket \text { a dog }](\mathrm{w})(\llbracket \text { is barking } \rrbracket(\mathrm{w}))] \\
& =\lambda \mathrm{w}\left[\lambda \mathrm{P} \exists \mathrm{x}[\mathrm{DOG}(\mathrm{w})(1)(\mathrm{x}) \wedge \mathrm{P}(\mathrm{x})]\left(\mathrm{BE} \_\mathrm{BARKING}(\mathrm{w})\right)\right] \\
& =\lambda \mathrm{w} \exists \mathrm{x}\left[\mathrm{DOG}(\mathrm{w})(1)(\mathrm{x}) \wedge \mathrm{BE} \_\mathrm{BARKING}(\mathrm{w})\right]
\end{aligned}
$$

This theory implies a meaningful relation between syntactic categories and semantic types: DPs have meanings that can directly be combined by functional application with verbal predicates; they are either referring expressions or quantifiers. And NPs are predicates that cannot directly be combined with verbal predicates.

Let us now turn to bare NPs, as in Dogs are barking. We have a type mismatch that has to be resolved. Type shift by $\exists$ allows for the following derivation: 
$\llbracket\left[\left[_{\mathrm{NP}}\right.\right.$ dogs $][$ are barking $\left.]\right] \rrbracket$

$\mathrm{a} . \stackrel{=}{=} \mathrm{w}[\{\llbracket$ dogs $\rrbracket(\mathrm{w})$, 【be barking $\rrbracket(\mathrm{w})\}]$, functional application impossible

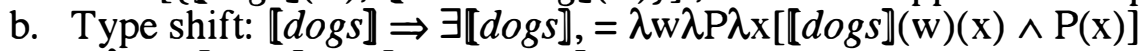

c. $=\lambda \mathrm{w}[\exists \llbracket$ dogs $\rrbracket(\mathrm{w})(\llbracket$ be barking $\rrbracket(\mathrm{w}))]$

d. $=\lambda w \exists x[\exists n[D O G(w)(n)(x)] \wedge$ BE_BARKING(w) $]$

We would have arrived at a similar result with a non-overt determiner with the meaning of the type shifter $\exists$. However, if we follow Chierchia and assume that type shif ting occurs as late, or as locally, as possible, only when the mismatch between the NP and the verbal predicate becomes apparent, type shif ting predicts that bare NPs have narrow scope. To see this, consider the example dogs aren't barking, in which dogs is moved over negation. I assume that $\chi_{1}$ is a type-neutral variable.

$$
\begin{aligned}
& \left.\llbracket\left[\text { dogs } \lambda 1\left[\text { aren't }\left[\mathrm{t}_{1} \text { barking }\right]\right]\right]\right] \\
& \left.\left.\mathrm{a} .=\lambda \mathrm{w}\left[\llbracket \lambda 1\left[\text { aren }^{\prime} t \mathrm{t}_{1} \text { barking }\right]\right](\mathrm{w})(\llbracket \text { dogs }](\mathrm{w})\right)\right]
\end{aligned}
$$

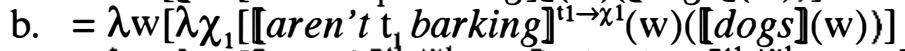

$$
\begin{aligned}
& \text { c. } \left.=\lambda \mathrm{w}\left[\lambda \chi_{1}\left[\llbracket \text { aren' }^{\prime} t\right]^{\mathrm{t} \rightarrow-\chi 1}(\mathrm{w})\left(\llbracket \mathrm{t}_{1} \text { barking } \rrbracket^{\mathrm{t}-\chi_{11}}(\mathrm{w})\right)\right](\llbracket \text { dogs } \rrbracket(\mathrm{w}))\right] \\
& \text { d. }=\lambda \mathrm{w}\left[\lambda \chi_{1}\left[\lambda \mathrm{p}[\neg \mathrm{p}]\left(\left\{\llbracket \mathrm{t}_{1} \rrbracket^{\mathrm{t} \rightarrow \chi^{1}}, \llbracket \text { barking } \rrbracket^{\mathrm{t}-\chi^{1}}(\mathrm{w})\right\}\right)(\llbracket \text { dogs } \rrbracket(\mathrm{w}))\right]\right. \\
& \text { e. }=\lambda \mathrm{w}\left[\lambda \chi_{1}\left[\lambda \mathrm{p}[\neg \mathrm{p}]\left(\left\{\chi_{1}, \mathrm{BE} \_B A R K I N G(\mathrm{w})\right\}\right)(\llbracket d o g s \rrbracket(\mathrm{w}))\right]\right. \\
& \text { f. }=\lambda \mathrm{w}[\lambda \mathrm{p}[\neg \mathrm{p}](\{\{\operatorname{dogs} \rrbracket(\mathrm{w}), \text { BE_BARKING }(\mathrm{w})\})] \text {, application impossible } \\
& \text { g. type shift by } \exists: \lambda w\left[\lambda \mathrm { p } [ \neg \mathrm { p } ] \left(\left\{\left[\exists\left[\operatorname{dogs} \rrbracket(\mathrm{w}), \mathrm{BE} \_\mathrm{BARKING}(\mathrm{w})\right\}\right)\right]\right.\right. \\
& \left.\mathrm{h} .=\lambda \mathrm{w}\left[\lambda \mathrm{p}[\neg \mathrm{p}](\lambda \mathrm{P} \exists \mathrm{x}[\llbracket \operatorname{dog} s](\mathrm{w})(\mathrm{x}) \wedge \mathrm{P}(\mathrm{x})]\left(\mathrm{BE} \_\mathrm{BARKING}(\mathrm{w})\right)\right)\right] \\
& \text { i. }=\lambda \mathrm{w}\left[\lambda \mathrm{p}[\neg \mathrm{p}]\left(\lambda \mathrm{P} \exists \mathrm{x}[\exists \mathrm{n}[\mathrm{DOG}(\mathrm{w})(\mathrm{n})(\mathrm{x})] \wedge \mathrm{P}(\mathrm{x})]\left(\mathrm{BE} \_ \text {BARKING }(\mathrm{w})\right)\right)\right] \\
& \text { j. }=\lambda \mathrm{w}[\lambda \mathrm{p}[\neg \mathrm{p}](\exists \mathrm{x}[\exists \mathrm{n}[\mathrm{DOG}(\mathrm{w})(\mathrm{n})(\mathrm{x})] \wedge \text { BE_BARKING(w) }]])] \\
& \mathrm{k} .=\lambda \mathrm{w}\left[\neg \exists \mathrm{x}\left[\exists \mathrm{n}[\mathrm{DOG}(\mathrm{w})(\mathrm{n})(\mathrm{x})] \wedge \mathrm{BE} \_\mathrm{BARKING}(\mathrm{w})\right]\right]
\end{aligned}
$$

In (70.a-f), the expressions are interpreted in the usual compositional fashion. For (d), notice that the meaning of traces are generally not world-dependent, and the meaning of lexical constants are not dependent on variable assignments. After applying the meaning of $\lambda 1$ [aren't $\mathrm{t}_{1}$ barking] to 【dogs](w), we have to compute the meaning of $\left\{\llbracket d o g s \rrbracket(w), B E \_B A R K I N G(w)\right\}$. The type mismatch can be resolved by

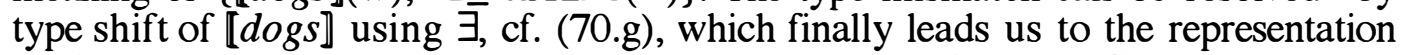
(70.k), in which negation has wide scope over the existential quantifier.

It is important for this derivation that type shifts occur locally. For this the variable representing the subject trace must not be typed. This predicts that with quantificational subjects, as in A dog isn't barking, we have two possible readings, as illustrated in (71). If the variable is of the type of entities, we arrive at the representation (71.c.i), in which the quantifier scopes over negation. If the variable is of the type of quantifier, we get the representation (71.c.ii), in which the quantifier is reconstructed in the position of the subject, and negation scopes over the quantifier.

$$
\begin{aligned}
& \text { a. } \left.\llbracket\left[[\text { a dog }] \lambda 1\left[\text { isn't }\left[\mathrm{t}_{1} \text { barking }\right]\right]\right]\right] \\
& \text { b. }=\lambda \mathrm{w}\left[\left\{\llbracket \text { a } \operatorname{dog} \rrbracket(\mathrm{w}), \llbracket \lambda 1\left[\text { isn't }\left[\mathrm{t}_{1} \text { barking }\right]\right] \rrbracket\right\}\right] \\
& \text { c. }=\lambda \mathrm{w}\left[\left\{\lambda \mathrm{P} \exists \mathrm{x}[\operatorname{DOG}(\mathrm{w})(1)(\mathrm{x}) \wedge \mathrm{P}(\mathrm{x})], \lambda \chi_{1}\left[\neg\left[\left\{\left[\mathrm{t}_{1}\right]^{\mathrm{t} \rightarrow \chi \chi^{1}}, \operatorname{BARKING}(\mathrm{w})\right\}\right]\right]\right\}\right] \\
& \text { i. take } \chi_{1} \text { as a variable for entities, } \mathrm{x}_{1} \text { : } \\
& \lambda w\left[\lambda \mathrm{P} \exists \mathrm{x}[\operatorname{DOG}(\mathrm{w})(1)(\mathrm{x}) \wedge \mathrm{P}(\mathrm{x})]\left(\lambda \mathrm{x}_{1}\left[\neg\left[\operatorname{BARKING}(\mathrm{w})\left(\mathrm{x}_{1}\right)\right]\right)\right]\right. \\
& =\lambda \mathrm{w} \exists \mathrm{x}[\operatorname{DOG}(\mathrm{w})(1)(\mathrm{x}) \wedge \neg[\mathrm{BARKING}(\mathrm{w})(\mathrm{x})]] \\
& \text { ii. take } \chi_{1} \text { as a variable for quantifiers, } Q_{1} \text { : } \\
& \lambda w\left[\lambda \mathrm{Q}_{1}\left[\neg\left[\mathrm{Q}_{1}(\operatorname{BARKING}(\mathrm{w}))\right]\right](\lambda \mathrm{P} \exists \mathrm{x}[\mathrm{DOG}(\mathrm{w})(1)(\mathrm{x}) \wedge \mathrm{P}(\mathrm{x})])\right] \\
& =\lambda \mathrm{w}[\neg[\lambda \mathrm{P} \exists \mathrm{x}[\operatorname{DOG}(\mathrm{w})(1)(\mathrm{x}) \wedge \mathrm{P}(\mathrm{x})](\operatorname{BARKING}(\mathrm{w}))]] \\
& =\lambda \mathrm{w}[\neg \exists \mathrm{x}[\operatorname{DOG}(\mathrm{w})(1)(\mathrm{x}) \wedge \operatorname{BARKING}(\mathrm{w})]]
\end{aligned}
$$

We may assume that in general, lower-type variables are preferred, which would predict the preference for the wide-scope interpretation of the quantifier. 
Instead of the type shift by $\exists$, we could also assume a type shift of the verbal predicate to make it applicable to a nominal predicate, like BE_BARKING $\Rightarrow$ $\lambda w \lambda P \exists x\left[B E \_B A R K I N G(w) \wedge P(x)\right]$, as proposed by van Geenhoven (1998). The predictions would be exactly the same as with local type shift of nominals by $\exists$.

Our strategy of interpreting bare NPs could also be applied to indefinite NPs with number words, such as two dogs, as they have the same semantic type as bare NPs like dogs. This would predict a narrow-scope interpretation of such NPs. However, we do find a wide-scope interpretation for sentences like Two dogs aren't barking, which is even the preferred reading. This means that NPs like two dogs cannot get their interpretation by type shifting. Rather, we should assume that number words can also be interpreted like determiners, with existential force, as in (72). The derivation of sentences like (73) is exactly parallel to (68).

$$
\begin{array}{ll}
\text { a. } \llbracket\left[{ }_{\mathrm{D}} t w o\right] \rrbracket & =\lambda \mathrm{w} \lambda \mathrm{R} \lambda \mathrm{P} \exists \mathrm{x}[\mathrm{R}(2)(\mathrm{x}) \wedge \mathrm{P}(\mathrm{x})] \\
\text { b. } \llbracket\left[\left[_{\mathrm{DP}}\left[{ }_{\mathrm{D}} t w o\right]\left[_{\mathrm{NP}}-\left[_{\mathrm{N}} d o g s\right]\right]\right] \rrbracket\right. & =\lambda \mathrm{w}[\llbracket w o](\mathrm{w})(\llbracket d o g s \rrbracket(\mathrm{w}))] \\
& =\lambda \mathrm{w}[\lambda \mathrm{R} \lambda \mathrm{P} \exists \mathrm{x}[\mathrm{R}(2)(\mathrm{x}) \wedge \mathrm{P}(\mathrm{x})](\mathrm{DOG}(\mathrm{w}))] \\
& =\lambda \mathrm{w} \lambda \mathrm{P} \exists \mathrm{x}[\mathrm{DOG}(\mathrm{w})(2)(\mathrm{x}) \wedge \mathrm{P}(\mathrm{x})]
\end{array}
$$

(73) $\llbracket\left[\left[_{\mathrm{DP}}\left[\mathrm{D}_{\mathrm{D}}\right.\right.\right.$ two $]\left[\mathrm{NP}_{-}\left[_{\mathrm{N}}\right.\right.$ dogs $\left.\left.]\right]\right][$ are barking $\left.\left.]\right]\right]$ $=\lambda \mathrm{W} \exists \mathrm{x}\left[\operatorname{DOG}(\mathrm{w})(1)(\mathrm{x}) \wedge \mathrm{BE} \_\right.$BARKING $\left.(\mathrm{w})\right]$

Analyzed in this way, we predict that wide-scope interpretations of expressions like two dogs are possible. The fact that they are preferably interpreted with wide scope can be taken to indicate that they have to be interpreted as DPs, and not as NPs, if possible. The general reason for this is that the DP interpretation avoids the otherwise necessary type shift.

The type-shift account for bare plurals, in either the version developed here or in Chierchia's original version, appears problematic because there is an indefinite plural and mass noun determiner, some, as in some dogs or some milk. Why doesn't some block the application of the type shifter $\exists$ ? Following the logic of the blocking principle, some must express more than just existential quantification. Possible differences are that some (and perhaps indefinite determiners in general) introduce discourse referents (Arik Cohen, pers. comm.), or that some introduces a choice function, thus allowing for wide scope interpretations (cf. Chierchia (1999), also von Heusinger (1997), Reinhart (1997), Winter (1997)). Example (74) shows that, even under a narrow-scope interpretation of the subject DP, we get a widescope interpretation if the choice function $f$, which maps a predicate $\mathrm{P}$ to an entity that $\mathrm{P}$ applies to, is existentially bound with wide scope.

$$
\begin{aligned}
& {\left[\left[_{\mathrm{DP}} \text { Some }\left[{ }_{\mathrm{NP}}\left[{ }_{\mathrm{N}} \text { dogs }\right]\right]\right] \text { aren't barking }\right] .} \\
& \lambda w \exists f\left[\neg\left[\mathrm{BE} \_\mathrm{BARKING}(\mathrm{w})(f(\lambda \mathrm{x} \exists \mathrm{n}[\mathrm{DOG}(\mathrm{w})(\mathrm{n})(\mathrm{x})]))\right]\right]
\end{aligned}
$$

We can apply similar reasoning to the case of Brazilian Portuguese (cf. Schmitt and Munn (1999), which has bare singular indef inites in addition to an indef inite article. Bare singulars have narrow scope, which argues that they undergo existential type shifting, whereas indefinite article induces wide scope readings, which is evidence that they are interpreted by choice functions.

Evidence for the forced choice-function interpretation comes from the fact, observed in Kratzer (1998), that indefinite NPs with the determiner some do not allow for characterizing statements, cf. (75). The reason is that the choice function reduces the domain of the generic operator to a singleton, which violates a restriction against quantification, cf. de Swart (1991).
a. Some dog barks.
b. Some dogs bark. 
Wide-scope readings that cannot be captured by LF movement due to island violations also occur with other indefinite NPs, such as a dog or two dogs, cf. Abusch (1993). They hardly occur with bare NPs. We can take this as evidence that the choice function are bound to the presence of a determiner, that is, to a DP.

Recall that Chierchia, following Carlson, observed wide-scope interpretations with some bare NPs such as parts of that machine and persons in this building:

a. Parts of that machine aren't working.

b. The police is looking for persons in this building.

Chierchia argued that such NPs do not correspond to kinds, hence cannot use ${ }^{n}$ as a type shifter, and instead use $\exists$. In our current theory, $\exists$ is the regular type shifter for bare NPs, and hence this explanation does not work. But there is an alternative: Observe that these NPs refer to a finite, typically fixed, set of entities. In such cases, the determiner some, which otherwise induces specific interpretations in the context of opacity predicates, would receive a partitive interpretation, in which it contrasts with other proportional quantifiers such as most and all. The sentence Some parts of that machine aren't working then implicates that not all parts of that machine aren't working, and the sentence the police is looking for some persons in this building implicates that the police isn't looking for all persons in this building. As some does not have the reading that normally distinguishes it from bare NPs (say, the choice function interpretation), it doesn't block possible type shifts that would lead to such readings. We can assume that choice function readings can be generated by type shifts, but are blocked by choice function some in cases like The police is looking for drug dealers. We can furthermore assume that some has a preferred partitive reading in case the head noun refers to a finite set, as in persons in this building. In this case, then, the type shift leading to a choice function interpretation is not blocked by any overt determiner.

\subsection{Kind-referring NPs and reflexive and control anaphora}

Bare NPs can refer to kinds, cf. (8.a). We follow Chierchia for such cases and assume a type shift by the down operator, $\cap$, now defined as in (77) as a partial individual concept that is defined for those worlds $w$ for which $\underline{P}$ has a greatest element.

$$
\underline{\mathrm{P}}=\lambda \mathrm{w}[\mathrm{l} \underline{\mathrm{P}}(\mathrm{w})]
$$

Predicates like extinct have argument slots that require individual concepts, hence their arguments do not have to be applied to a possible world. This is similar to the analysis of verbs like rise and change in Montague (1973).

$$
\begin{aligned}
& \llbracket \text { Dodos are extinct } \rrbracket=\lambda \mathrm{w}[\{\llbracket \text { be extinct } \rrbracket(\mathrm{w}),[\text { dodos } \rrbracket\}] \\
& \text { by type shif } \mathrm{t}: \quad=\lambda \mathrm{w}[\llbracket \text { be extinct }](\mathrm{w})(\Upsilon[\text { dodos }])] \\
& =\lambda w\left[B E \_ \text {EXTINCT }(w)\left(\lambda w^{\prime}\left[\imath \lambda x \exists n\left[D O D O\left(w^{\prime}\right)(n)(x)\right]\right]\right)\right]
\end{aligned}
$$

The down operator as defined in (77) is not restricted to cumulative predicates; for example, \one dog】 is defined, and stands for an individual concept that maps every world that has exactly one dog to that dog. There is no need for a converse operator $\checkmark$ that maps kinds to instances. This is possible because the down operator does less work in the current system: It is only used for true kind predications.

In addition to predicates that strictly apply to kinds, there are predicates that can apply to kinds or to regular objects. Krifka et al. (1995) have identified several such uses, such as the following: 
(79) a. Rats reached Australia in 1770.

b. American customers bought 75,000 BMWs last year.

Assuming that predicates like reach or buy are not intensional like be extinct or invent, we have the following interpretation:

$$
\begin{aligned}
& \text { [Rats reached Australia in 1770] } \\
& =\lambda w[\text { REACH_AUSTRALIA_IN_1770(w) }(\text { [rats }](\mathrm{w}))] \\
& =\lambda \mathrm{w}\left[\mathrm{REACH} \_ \text {AUSTRALIA_IN_1770 }(\mathrm{w})(\mathrm{l} \lambda \mathrm{x} \exists \mathrm{n}[\mathrm{RAT}(\mathrm{w})(\mathrm{n})(\mathrm{x})])\right]
\end{aligned}
$$

This means, literally, that the sum individual consisting of all rats reached Australia in 1770. While false in an inclusive sense, it is true in the sense that an important property of avantgarde specimens is attributed to the sum of all rats. Notice that we can say The rats reached Australia in 1770 with a similar interpretation.

Let us turn now to the argument of Rooth (1985) for the kind-referring analysis, the observation that apparently non-generic bare NPs can bind kindreferring reflexives and control PRO, cf. (17), (18). We can deal with such examples by assuming that bare NPs basically denote properties, that reflexives or PRO can instantiate the same property as the antecedent, and that any type shifts are triggered locally. Consider the following example:

Martians ${ }_{1}$ claimed $\left[\mathrm{PRO}_{1}\right.$ to be almost extinct].

a. $=\lambda \mathrm{w}[\{[$ Martians $](\mathrm{w})$,

b. $=\lambda w[\{[$ Martians $](\mathrm{w})$,

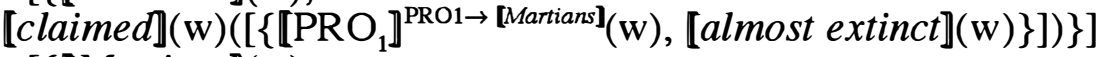

【claimed $\rrbracket(\mathrm{w})([\{[$ Martians $\rrbracket(\mathrm{w}), \llbracket$ almost extinct $\rrbracket(\mathrm{w})\}])\}]$

c. type mismatch (twice) with [Martians], requiring type shifts by $\exists$ and ${ }^{n}$ : $=\lambda \mathrm{w}[\{\exists[$ Martians $](\mathrm{w})$, [claimed $](\mathrm{w})\left(\left[\left\{{ }^{\mathrm{N}}[\right.\right.\right.$ Martians $](\mathrm{w})$, [almost extinct $\left.\left.\left.\left.\left.](\mathrm{w})\right\}\right]\right)\right\}\right]$

d. $=\lambda w\left[\exists[\right.$ Martians $](w)\left(\operatorname{CLAIMED}(\mathrm{w})\left(\operatorname{ALMOST} \_\operatorname{EXTINCT}(\mathrm{w})(\cap[\right.\right.$ Martians $\left.\left.])\right)\right]$

e. $=\lambda w[\lambda P \exists x[\exists n[\operatorname{MARTIAN}(w)(n)(x) \wedge P(x)]$

$\left.\left(\operatorname{Claimed}(w)\left(\operatorname{almost} \_\operatorname{eXtinct}(w)\left({ }^{\prime} \lambda w^{\prime} \lambda y \exists n\left[\operatorname{Martian}\left(w^{\prime}\right)(n)(y)\right]\right)\right)\right)\right]$

f. $=\lambda w \exists x[\exists n[\operatorname{MARTIAN}(\mathrm{w})(\mathrm{n})(\mathrm{x}) \wedge$

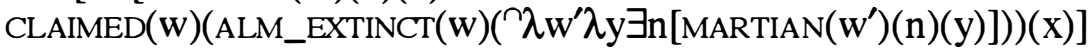

In (81.a) Martians is interpreted as a property in subject position, and co-indexed with PRO. This is spelled out in (b). Two type shifts are required, the first one shifting the subject to an existential quantifier, the second one shifting PRO to a kind, cf. (c). This leads us to the correct interpretation: There were some Martians $\mathrm{x}$ that claimed that the kind Martians are almost extinct. Examples like (14), which imply a mixed object and kind reading, can be treated in a similar way.

\subsection{The role of information structure}

In cases like (79.a), a type shift by $\exists$ would be possible as well. Not so for (79.b), which would result in a completely different interpretation. Why does the type shift by $\exists$ not happen here? I would like to suggest, following Krifka et al. (1995) and Cohen \& Erteschik-Shir (2002), that information structure plays an important role. In order for type shift by the down operator to occur, the nominal predicate must be a topic. The kind-referring readings of $(79 . \mathrm{a}, \mathrm{b})$ require a prosodic structure typical for topic-comment structures: There are two prosodic phrases, one on the subject, one on the object. Kind-referring readings of bare NPs in object position are disfavored because this is not a regular topic position; cf. *Shockley invented transistors. Also, in languages with pragmatically determined word order, bare NP 
subjects are often interpreted as kind-referring when pre-verbal, and as existential when post-verbal, again an effect that can be ascribed to topichood (cf. Doron 2003 for Hebrew, Hindi and Brazilian Portuguese).

Appealing to information structure also helps to explain the observation by Carlson that the nature of the verbal predicate can decide whether a bare NP is interpreted generically or as involving specimens (cf. the first argument in section 2.1). He appealed to a distinction between individual-level and stage-level predicates, which, in other frameworks, corresponds to a distinction between episodic predicates with a situation argument, and stative predicates without it (cf. Kratzer (1995)). As a general rule of discourse coherence, every sentence must have a topic. The situation argument can satisfy the topic requirement, which is the case in utterances like Dogs are barking that are about contextually given situations. The bare NP dogs is not a topic, hence can be interpreted by existential type shift. In stative sentences, which do not have a situation argument, another constituent must be the topic. For a sentence like Dogs are widespread, the most plausible candidate is the bare NP dogs, which then cannot be interpreted by existential type shift $\exists$, and must be interpreted by the generic type shift ${ }^{n}$ instead.

Information structure also plays a role in characterizing statements like Dogs bark or A dog barks. In Krifka (2001) I argued that indefinite NPs in the restrictor have topicality features, and that the restrictor is a topic. The topicality requirement for restrictors can explain the widespread use of definite articles in Romance languages, which is probably due to the fact that deaccenting cannot be used as freely as in English to mark topicality. Also, it can explain certain puzzling complexity requirements for bare NPs in Italian and Spanish, cf. Longobardi (2001), GutierrezRexach \& Silva-Villar (2002).

(82) a. Elefanti di colore bianco possono creare grande curiosità.

b. *Elefanti possono creare grande curiosità.

'(White-colored) elephants can create great curiosity.'

(83) a. Minirobots hacen el trabajo con igual cualidad.

b. *Robots hacen el trabajo con igual cualidad.

'(Mini)robots do the job with the same quality.'

Complex bare NPs may form a prosodic phrase on their own; this is necessary for interpreting the phrase in the restrictor of a quantifier (cf. the notions of integration and separation in Jacobs (1999)).

\subsection{Definite generic NPs and taxonomic NPs}

This article is abolut bare NPs, but let me add some thoughts about definite generic NPs, like the dog. While the arguments of Dayal and Chierchia are quite compelling that they involve reference to groups, the meaning of such NPs cannot be derived in a systematic way (cf. section 3.4).

Dayal (2002) makes the interesting proposal that it can be obtained via the taxonomic interpretation of count nouns. This use of count nouns refers to kinds instead of regular objects; an example is There are two bears in Alaska, the black bear and the grizzly. Krifka et al. (1995) and Krifka (1995) proposed that count nouns also have a reading in which they apply to subspecies. The relation BEAR(W) can be applied to numbers and bear subspecies, e.g. BEAR(W)(1)(URSUS_HORRIBILIS). Dayal proposes in addition that it can be applied to the bear species URSUS itself. The kind-referring use of the bear then can be derived by the usual meaning of the, as $\operatorname{tx}[\operatorname{BEAR}(\mathrm{w})(1)(\mathrm{x})]$, if the domain of quantification, left implicit here, does not contain any bear subspecies or specimens. 
In order to adopt this proposal, we assume that the kinds that can be denoted by singular definites are related to kind individuals, which are atomic individuals that form a special sort, similar to the set $\mathrm{K}$ in Chierchia (1998). I will use the down arrow $\downarrow$ to denote this relation: $\downarrow \lambda w i \lambda x \exists n[\operatorname{BEAR}(w)(n)(x)]=$ URsus. Comparatively few individual concepts have this double life; this captures the insight that only established kinds can be referred to by definite singulars (cf. the coke bottle vs. the green bottle; Carlson (1977), attributed to Partee). Consequently, we only have a sortal distinction, and not a type distinction, between the different arguments of a count noun predicate like BEAR(w)(1). We can refer to singular kinds by names, like Ursus or Man or, following Dayal, by regular definite descriptions like the bear if the quantificational domain is suitably restricted. It appears that mass nouns generally can be used as names for atomic kinds, which explains the lack of articles in sentences like Gold is shiny. Presumably, this is because mass nouns are categorized as NPs in syntax, in contrast to count nouns, which are categorized as $\mathrm{N}$ due to the more frequent non-generic uses they need to have their number argument filled. German can use definite articles with kind-referring mass nouns, as in Das Gold glänzt, which can be explained by the fact that German can use definite articles with names in general, cf. Krifka et al. (1995). In Hebrew, bare singular count nouns can also refer to atomic kinds, cf. Doron (2003), which might indicate a double function of count nouns as measure relations and as names.

What properties do atomic kinds have? I suggest that properties of regular kinds can generally be applied to corresponding atomic kinds; hence we have the dodo is extinct. Also, properties that the predicates related to regular kinds have are ascribed to the corresponding atomic kinds; thus we have the dodo had a purple beak. General number restrictions have to be followed; so while we have dodos had a purple beak, by distributive interpretation, and dodos had black beaks, by cumulative interpretation, the dodo had purple beaks suggests that a dodo had more than one beak. This is a plausible reason why sentences like * the dodo was numerous are bad; numerous has to be applied to a sum individual, which the atomic kind does not provide. Contrast this with the dodo was rare, which can be used with singular generics. This is just as in A dodo is rare vs. *A dodo is numerous. Presumably, be rare has to be interpreted as 'it is a rare event to find instances of _, where the blank position can contain anything that has members, elements, or specimens. We have also observed that characterizing sentences of the rule-and-regulations variety cannot be expressed with definite generic NPs, cf. (4.a). Such statements essentially state conditions under which an entity belongs to a class, e.g. whether it is a gentleman or not. For this, we crucially need to refer to the class, which can naturally be done by bare NPs or by indefinites (perhaps via type shift with BE), but not with atomic kinds.

\section{Conclusion}

This paper set out with the controversy around the semantic nature of bare NPs in English: Are they kind referring, or ambiguous between a kind-referring and an indefinite interpretation. The answer, which required a type shift framework as developed in Chierchia (1998), is: Bare NPs are basically properties, hence they are neither kind-referring nor indef inites. They can be shifted to one or the other interpretation in appropriate linguistic contexts. They cannot be called ambiguous either, as their basic meaning is always a property. In a sense, all disjuncts in the title of this talk are true: Bare NPs have kind-ref erring interpretations, they have indefinite interpretations, hence they have both kind-referring and indefinite. But basically they are neither one nor the other. The type shifting framework is flexible enough to make all these statements true. 


\section{References}

Abusch, Dorit. 1993. The scope of indefinites. NLS 2, 83-135.

Abney, Steven. 1987. The English noun phrase in its sentential aspect, Doctoral dissertation, MIT.

Barker, Chris. 1992. Group terms in English: representing groups as atoms. Journal of Semantics 9: 69-93.

Carlson, Greg N. 1977. Reference to kinds in English, University of Massachusetts, Doctoral Disseration. Also 1978, Indiana University Linguistics Club.

Carlson, Greg N. 1989. On the semantic composition of English generic sentences. In Properties, types and meaning. Volume 2: semantic issues., eds. G. Chierchia, B. Partee \& R. Turner, 167-192. Dordrecht: Kluwer.

Carlson, Greg N. 1995. Truth conditions of generic sentences: Two contrasting vies. In Carlson \& Pelletier (eds.), 224-237.

Carlson, Greg N. \& Pelletier, Francis J. (eds). 1995. The generic book. Chicago, London: The University of Chicago Press.

Cheng, Lisa Lai-Shen, and Sybesma, Rint. 1999. Bare and not-so-bare nouns and the structure of NP. Linguistic Inquiry 30:509-542.

Chierchia, Gennaro. 1998. Reference to kinds across languages. Natural Language Semantics 6: 339-405.

Cohen, Ariel. 2002. On the generic use of indefinite singulars. Journal of Semantics 18.

Cohen, Ariel, and Erteschik-Shir, Nomi. 2002. Topic, focus and the interpretation of bare plurals. Natural Language Semantics 10.

Condoravdi, Cleo. 1992. Weakly and strongly novel noun phrases. Paper presented at West Coast Conference of Formal Linguistics 11, UCLA.

Dayal, Veneeta. 1992. The singular-plural distinction in Hindi generics. SALT II, OSU Working Papers in Linguistics, Columbus.

Dayal, Veneeta. 2002. Number marking and (in)definiteness in kind terms. Ms. Ms., Rutgers University. To appear in Linguistics \& Philosoophy.

de Swart, Helen. 1991. Adverbs of quantification: A generalized quantifier approach, Doctoral Dissertation, University of Groningen.

Doron, Edit. 2003. Bare singular reference to kinds. SALT 13.

Gerstner-Link, Claudia, and Krifka, Manfred. 1993. Genericity. In Handbuch der Syntax, eds. J Jacobs et al., 966-978. Berlin: Walter de Gruyter.

Gerstner-Link, Claudia. 1995. Über Generizität. Generische Nominalausdrücke in singulären und generellen Aussagen. München: Wilhelm Fink Verlag.

Gutierrez-Rexach, Javier, and Silva-Villar, Luis. 2002. Prosodic and morphological focus in Spanish bare plurals. Ms.

Heim, Irene. 1982. The semantics of definite and indefinite noun phrases, Doctoral dissertation, University of Massachusetts at Amherst. Also New York: Garland.

Heim, Irene, and Kratzer, Angelika. 1998. Semantics in generative grammar. London: Blackwell.

Jacobs, Joachim. 1999. Informational autonomy. In Focus. Linguistic, cognitive and computational perspectives, eds. P. Bosch and R. van der Sandt, 56-81. Cambridge: Cambridge University Press.

Kleiber, G. 1989. 'Le' generique: Un Massif?', Langage 94, 73-113.

Kratzer, Angelika. 1995. Stage-level and individual level predicates. In Carlson \& Pelletier (eds.), 125-175.

Kratzer, Angelika. 1998. Scope or pseudoscope? Are there wide-scope indefinites? In Events and grammar, ed. S. Rothstein, 163-196. Dordrecht: Kluwer. 
Krifka, Manfred. 1989. Nominalreferenz und Zeitkonstitution. Zur Semantik von Massentermen, Pluraltermen und Aspektklassen. München: Wilhelm Fink.

Krifka, Manfred. 1995. Common nouns: a contrastive analysis of Chinese and English. In Carlson \& Pelletier (1995), 398-411.

Krifka, Manfred, Pelletier, F. J., Carlson, Greg N., ter Meulen, Alice, Chierchia, Gennaro, and Link, Godehard. 1995. Genericity: an introduction. In Carlson \& Pelletier (1995), 1-124.

Krifka, Manfred. 2001. Non-novel indefinites in adverbial quantification, eds. C. Condoravdi and G. Renardel der Lavalette, 1-40. Stanford: CSLI Press.

Krifka, Manfred. 2002. Be brief and vague! And how Bidirectional Optimality Theory allows for verbosity and precision. In Sounds and systems: studies in structure and change. eds. D. Restle \& D. Zaefferer, 439-458. Berlin: Mouton de Gruyter.

Kuroda, S.-Y. 1972. The categorical and the thetic judgment, Evidence from Japanese syntax. Foundations of Language.

Landman, Fred. 1989. Groups. Linguistics and Philosophy 12:559-605.

Lawler, John. 1973. Studies in English generics.vol. 1. Ann Arbor: University of Michigan Papers in Linguistics.

Link, Godehard. 1983. The logical analysis of plurals and mass terms: A latticetheoretical approach. In Meaning, use and the interpretation of language, eds. R. Bäuerle, C. Schwarze and A. von Stechow, 303-323. Berlin, New York: Walter de Gruyter.

Longobardi, Giuseppe. 2001. How comparative is semantics? A unified parametric theory of bare nouns and proper names. Natural Language Semantics 9:335-369.

Montague, Richard. 1973. The proper treatment of quantification in ordinary English. In Approaches to Natural Language. Proceedings of the 1970 Stanford workshop on grammar and semantics, eds. K.J.J. Hintikka, J.M.E. Moravcsik and P. Suppes, 221-242. Dordrecht: Reidel.

Partee, Barbara. 1987. Noun phrase interpretation and type-shifting principles. In Studies in Discourse Representation Theory and the Theory of Generalized Quantifiers, ed. J. Groenendijk, 115-143. Dordrecht: Foris.

Reinhart, Tanya. 1997. Quantifier scope: How labor is divided between QR and choice functions. Linguistics and Philosophy 20: 335-397.

Rooth, M. 1985. Association with focus, University of Massachusetts at Amherst: Ph.D. dissertation.

Rooth, Mats. 1987. Noun phrase interpretation in Montague Grammar, File Change Semantics, and Situation Semantics. In Generalized quantifiers. Linguistic and logical approaches., ed. Peter Gärdenfors, 237-268. Dordrecht: Reidel.

Rooth, Mats. 1995. Indefinites, adverbs of quantification and focus semantics. In The Generic Book, eds. G. N. Carlson and F. J. Pelletier, 265-291. Chicago: Chicago University Press.

Schmitt, Cristina, and Munn, Alan. 1999. Against the nominal mapping parameter: Bare nouns in Brazilian Portuguese. NELS 29.

ter Meulen, Alice. 1980. Substance, quantities and individuals: A study in the formal semantics of Mass Terms. Bloomington: Indiana University Linguistics Club.

van Geenhoven, Veerle. 1998. Semantic incorporation and indefinite descriptions. Stanford: CSLI Publications.

von Heusinger, Klaus. 1997. Salienz und Referenz. Berlin: Akademie Verlag.

Wilkinson, Karina. 1991. Studies in the semantics of generic noun phrases, Doctoral Dissertation, University of Massachusetts at Amherst.

Winter, Yoad. 1997. Choice functions and the scopal semantics of indefinites. Linguistics and Philosophy 20, 399-467. 